\title{
Diagnosis and Surgical Management of Intestinal Intussusception by Open Lumina Technique in Dairy Heifers (Bos taurus)
}

\author{
Sukhnandan Singh ${ }^{1}$, H. R. Bhardwaj ${ }^{1}$, M. M. S. Zama ${ }^{2}$, Ankur Sharma ${ }^{1}$, \\ Pankaj Gupta ${ }^{1}$, Ashok Kumar ${ }^{3}$ and Kamal Sarma ${ }^{4}$
}

${ }^{1}$ Department of Veterinary Surgery and Radiology, ${ }^{2}$ Department of Veterinary Sciences and Animal Husbandry, ${ }^{3}$ Department of Teaching Veterinary Clinical Complex, ${ }^{4}$ Department of Veterinary Anatomy and Histology, Sher-e-Kashmir University of Agricultural Sciences and Technology-Jammu (SKUAST-J), R.S. Pura-181102, India

*Corresponding author

\section{Keywords \\ Intussusception, Heifers, Open lumina technique, side-to-side entero- anastomosis \\ Article Info \\ Received: 09 October 2021 Accepted: 05 November 2021 Available Online: 10 November 2021}

\section{A B S T R A C T}

The present study was conducted in ten dairy heifers (Bos taurus) suffering from intestinal intussusception. All these cases exhibited the clinical signs of bouts of colicky pain for 6-12 hours followed by anorexia and cessation of faeces. In all cases, the onset of disease was between 72-120 hours. Per-rectal palpation revealed spiral-shaped mass and distended intestinal loops. Ultrasonographically, distended loops, ileus, passive movement of ingesta and presence of peritoneal fluid were consistent findings. The diagnosis of intestinal intussusception was made on the basis of clinical signs, per-rectal palpation and trans-abdominal ultrasonography. Further it was confirmed on full abdominal right flank exploratory laparotomy. All the heifers were subjected for standing right flank laparotomy under linear infiltration of local anaesthesia followed by exteriorization and resection of intussucepted intestinal mass. The side-to-side entero-anastomosis was done by open lumina technique using gastro-intestinal anastomotic (GIA) stapled devices. Signalment, duration of surgery and anastomotic time were recorded in all cases. Thus, Intestinal intussusception in dairy heifers was diagnosed on the basis of clinical signs, per-rectal palpation, trans-abdominal ultrasonography which was further confirmed by full abdominal right flank exploratory laparotomy. The GIA staples applied for side-to-side entero-anastomosis by open lumina technique took less total surgical and anastomotic time. Moreover, there was reduction in tissue trauma/manipulation and in contamination by intestinal contents. The closure of bowel was easy and secured. GIA staples can be used effectively for entero-anastomosis in cattle affected with intestinal intussusception. 


\section{Introduction}

Intussusception is an intestinal affection in which one segment of intestine telescopes inside of another which leads to intestinal obstruction (Pearson, 1971; Smart et al., 1977 and Constable et al., 1997). It typically develops secondary to changed intestinal motility and the process occurs mostly in the direction of peristalsis. Although intussusception can occur in any part of the alimentary tract, the most common location is the intestine (Horne, 1991). Most important clinical symptoms exhibited by affected cows are bouts of colic followed by reduced feed and water intake, cessation of faeces and abdominal distention (Smith, 1980). It can be diagnosed by per-rectal palpation of tightly coiled loops of intestines and/or transabdominal ultrasonography evidenced by presence of a bull-eye pattern and/or distended intestinal loops and presence of increased peritoneal fluid (Imran et al., 2011; Tharwat, 2012; Mestry et al., 2012; Khalphallah et al., 2016 and Mann et al., 2019).

Surgically, intussusception is reported to be repaired by end-to-end or side-to-side enteroanastomosis either by using conventional hand-sewn sutures (Constable et al., 1997; Dabak et al., 2001 and Fontaine and Rodgerson, 2001) or by GIA stapling devices. However, former surgical techniques have been reported to cause more tissue manipulation and are time consuming. Moreover, it also leads to overexposures of surgical site, and that further increases augmentation of bacterial load, leading to conditions like peritonitis, adhesions, leakage and ultimately mortality (Ralphs et al., 2003). The later technique of entero-anastomosis using stapler devices is a technological advancement that causes less tissue injury and lesser time for surgical procedure. Moreover, it also decreases the anastomotic leak complications (Santo et al., 2011).
Complication rates are less following the use of stapling devices provided they are applied correctly by a trained surgeon (Smeak and Crocker, 1997).

The everting triangulating end-to-end enteroanastomosis (McGinty et al., 1979), the inverting end-to-end entero-anastomosis (Nance, 1979) and the antiperistaltic side-toside (functional end to end) enteroanastomoses (Ravitch and Steichen, 1972) are three described techniques out of these the antiperistaltic side-to-side entero-anastomosis is considered as a technique of choice (Steichen and Ravitch, 1984 and Ullman 1994). The antiperistaltic side-to-side anastomosis further includes the open lumina technique (Chassin et al., 1984), functional end-to-end entero-anastomosis (Yamamoto and Keighley, 1999), offset method (Steichen and Ravitch, 1984) and one-stage functional end-to-end entero-anastomosis and resection (Ravitch et al., 1974).

The clinical application of surgical stapling as a technique for management of intestinal intussusception in dairy animals is poorly reported. In this study, open lumina enteroanastomosis was performed in 10 dairy heifers.

\section{Materials and Methods}

\section{Diagnosis}

The present study was conducted on ten dairy heifers affected with intestinal intussusception. Intussusception was diagnosed on the basis of history, clinical signs, per-rectal palpation and transabdominal Ultrasonographic examination.

\section{Surgical management}

All the dairy heifers were prepared for aseptic surgery and subjected to standing right-flank 
laparotomy under linear local infiltration followed by resection of intussuscepted mass and entero-anastomosis by open-lumina technique using gastrointestinal anastomosis (GIA) stapling device. The GIA stapling device was sterilized in a formalin chamber. In each case, the entero-anastomosis was performed with a multi-use linear cutter stapling gun using single use reloadable stapling units (SULU) (Fig. 2). The intussuscepted mass explored and gently exteriorized through laparotomy incision (Fig. 1; B). Mesentery was infiltrated with $2 \%$ injection lignocaine hydrochloride. The major mesenteric blood vessels were identified and ligated with Polyglactin 910 synthetic absorbable suture material No. 1. Doyen intestinal clamps were applied on intestinal lumen to prevent the spillage of contents from the oral side. The exteriorized intussuscepted mass was resected out followed by repairing of mesenteric ends with Polyglactin 910 No. 1. Then the two limbs of stapler were inserted into each lumen of the bowel to be anastomosed. The open ends of the bowel were aligned evenly on the forks of GIA stapler so that the anti-mesenteric surfaces were in apposition. The two limbs of the stapler were engaged and locked (Fig. 1; C). The stapler was "fired" resulting in two double-staggered staple lines joining the two pieces of bowel; simultaneously, the knife blade created a stoma by dividing the anastomosed bowel between the two doublestaple lines (Fig. 1; D). Then the stapler was loaded with new SULU and the forks of the stapler were positioned around the anastomosed bowel at $90^{\circ}$ to its long axis and adjacent to its opening. The two limbs of the stapler were engaged and locked $1 \mathrm{~cm}$ ventral to the previously stapled edges (Fig. 1; E). The stapler was "fired" resulting in completion of the anastomosis procedure (Fig. 1; F \& G). Total duration of surgery was recorded as time from the skin incision up to the last suture on skin. Anastomotic time was recorded from the start of anastomosis up to the last suture of anastomosis. Post-operatively injection Enrofloxacin@2.5mg/kg body weight and injection Meloxicam @ $0.5 \mathrm{mg} / \mathrm{kg}$ body weight intramuscularly for 5 days. Injection 5\% Dextrose Normal Saline was given for three consecutive days postoperatively. Antiseptic dressing of the wound was done with $5 \%$ povidone iodine lotion daily.

The total duration of surgery and anastomotic time were statistically analyzed by one-way ANOVA using SPSS 16.0 version.

\section{Results and Discussion}

All the dairy heifers were presented with a history of the bouts of violent colicky pain exhibited by rolling on ground, stretching of body and legs, frequently sitting and standing up, paddling of limbs, kicking at belly and arching of the back. Reduced water intake was observed in all heifers along with suspended rumination. There was complete anorexia and cessation of faeces. On per-rectal examination, mucoid discharge stained with blood was passed by affected cow-heifers; distended intestinal loops were palpated in 6 heifers whereas the intussuscepted mass was palpable in 4 heifers. Trans-abdominal ultrasonography of the right flank revealed distended intestinal loops, ileus and passive movement of ingesta, intestinal wall and presence of peritoneal fluid (Fig.3). The mean \pm S.E values of total duration of surgery ( $\mathrm{min}$ ) was $31.80 \pm 097$ and mean \pm S.E. value of anastomotic time $(\mathrm{min})$ was $5.60 \pm 0.22$.

All the dairy heifers were presented with a history of violent colicky pain which might have been occurred due to pressure on intestine caused by spasm associated motility disorder, distension of the intestinal part oral to intussusception due to the trapped fluid and gas produced from abnormal growth of bacteria. The visceral pain might have 
occurred due to activation of nociceptive mechano-receptors within the intestinal wall. The initial phase of severe abdominal pain might have been caused primarily by the tension on the mesentery as it is drawn into the intussuscipiens and it persisted for 6-12 hours. The abdominal pain may be related to the local congestion and oedema. Similar observations have been reported by many other workers (Imran et al., 2011; Tharwat, 2012; Mestry et al., 2012; Kushwaha et al., 2012; Milnes and McLachlan, 2015; Hussain et al., 2015; Khalphallah et al., 2016; Nichols and Facteau, 2017; Mir, 2018; Agne et al., 2018 and Mann et al., 2019). A history of anorexia was reported by other authors (Imran et al., 2011; Tharwat, 2012; Mestry et al., 2012; Kushwaha et al., 2012; Milnes and McLachlan, 2015; Hussain et al., 2015; Khalphallah et al., 2016; Nichols and Facteau, 2017; Mir, 2018; Agne et al., 2018 and Mann et al., 2019), Reduced water intake was reported by previous authors (Hussain et al., 2015; Mir, 2018 and Mann et al., 2019) and a history of cessation of faeces which might have been occurred due to telescoping of a portion of cranial intestine (intussusceptum) into the lumen of caudal adjacent bowel (intussuscipiens) which becomes the reason of mechanical obstruction in intestine. Other authors (Constable et al., 1997; Dharmaceelan et al., 2012; Smith, 2014 and Hussain et al., 2015) also reported similar findings. Rumination was suspended in all dairy heifers suffering from intestinal intussusception. Suspended rumination was expected to be due to atonic rumen (Papadopolous et al., 1985 and Mann et al., 2019).

On per-rectal examination empty rectum with no faeces was seen in all dairy heifers, passage of mucoid raspberry coloured and creamish mucoid discharge from rectum was recorded.
Raspberry colour may be attributed from sloughing of devitalized intestine mixed with mucus and faecal material (Smith, 1980) also faecal material consistency and colour could be related to number of days after which animal is presented. Similar findings has also been noticed by previous authors (Imran et al., 2011; Tharwat, 2012; Mestry et al., 2012; Kushwaha et al., 2012; Milnes and McLachlan, 2015; Hussain et al., 2015; Khalphallah et al., 2016; Mir, 2018; Mann et al., 2019 and Patel et al., 2019). However, distended intestinal loops were palpable in $(6 / 10)$ heifers, which is due to distension caused by gas and fluid present proximal to intussuscepted mass. Similar findings of distended intestinal loops palpable on perrectal examination has also been reported by other previous workers (Imran et al., 2011; Tharwat, 2012; Milnes and McLachlan, 2015; Hussain et al., 2015; Khalphallah et al., 2016; Nichols and Facteau, 2017; Mir, 2018 and Mann et al., 2019). Moreover, intussuscepted mass was palpable in 4 heifers, this might be due to after formation of intussusception more and more intestines are drawn forming intussusception, the mesentery becomes very tight, causing the involved bowel to spiral. Therefore, if the intussusception is palpable rectally, it feels like tightly-coiled loops of the intestine. Similar findings of palpable intussuscepted mass on per-rectal examination were reported by other authors (Imran et al., 2011; Mestry et al., 2012; Kushwaha et al., 2012; Hussain et al., 2015; Nichols and Facteau, 2017; Mir, 2018; Patel et al., 2019 and Mann et al., 2019).

On ultrasonography, distended intestinal loops, ileus, passive movement of ingesta, hyper-echoic intestinal wall and presence of increased peritoneal fluid was seen. Ileus was found in all the cases. 
Fig.1 Demonstration of Open lumina method via. GIA stapling device
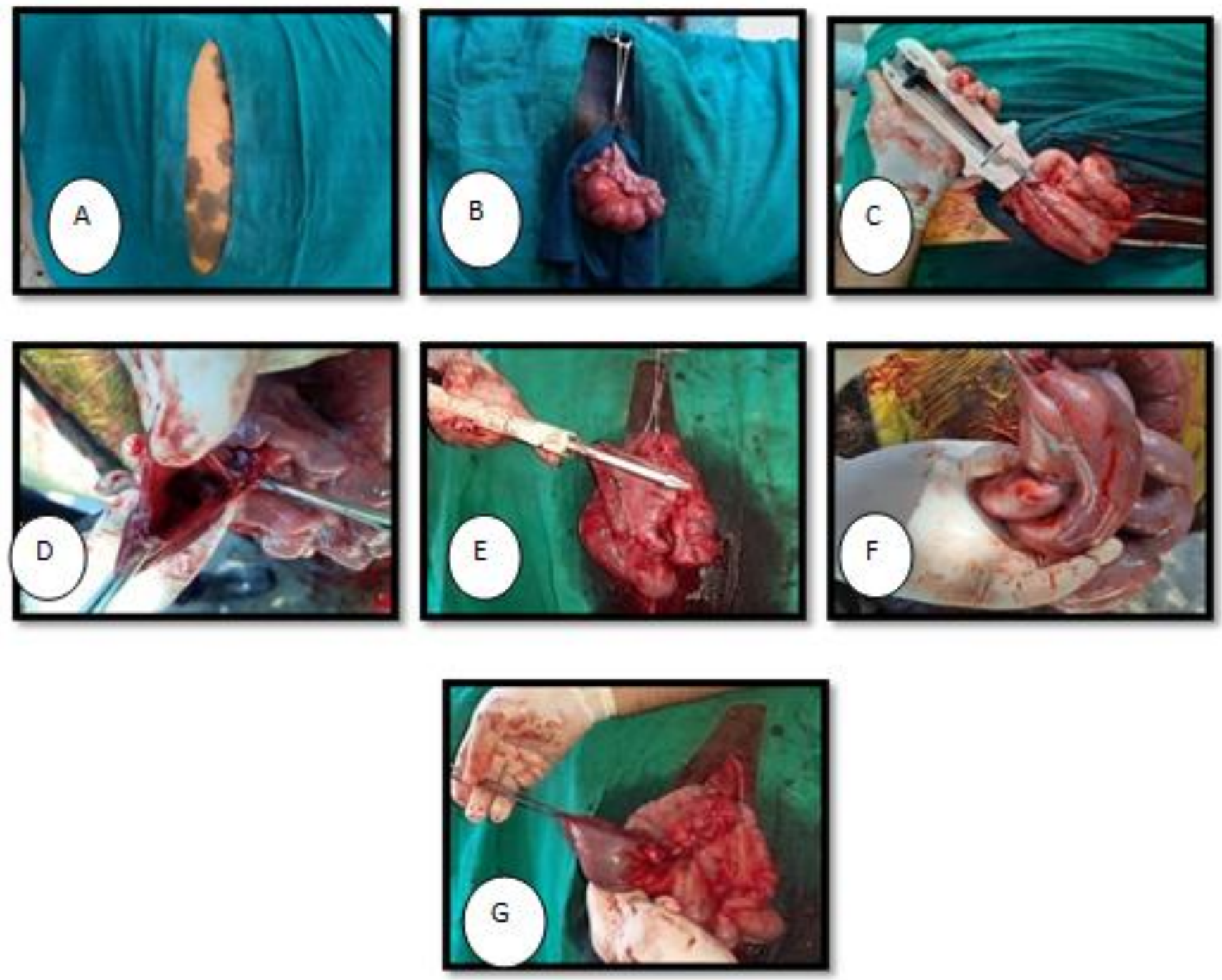

(A) Preparation and draping of surgical site. (B) Exteriorisation and packing of intussuscepted mass. (C) The stapler limbs were inserted into loops, the limbs of stapler were engaged and locked followed by firing. (D) Showing the lumen of the two portions of bowel following the initial firing of the stapler. The two double-staple lines can be seen clearly along with the stoma created between them by the action of the knife. (E) The reloaded stapler has been positioned across the bowel at $90^{\circ}$ to its long axis. The stapler is locked so that the two initial staple lines are offset and not adjacent to each other. The portions of bowel containing the two stay sutures are those which will be sacrificed following the second firing of the stapler and (F \& G) After completing anastomosis. 
Fig.2 Reach linear cutter 80 along with Multifire (SULU) $4.8 \mathrm{~mm}$ cartridge

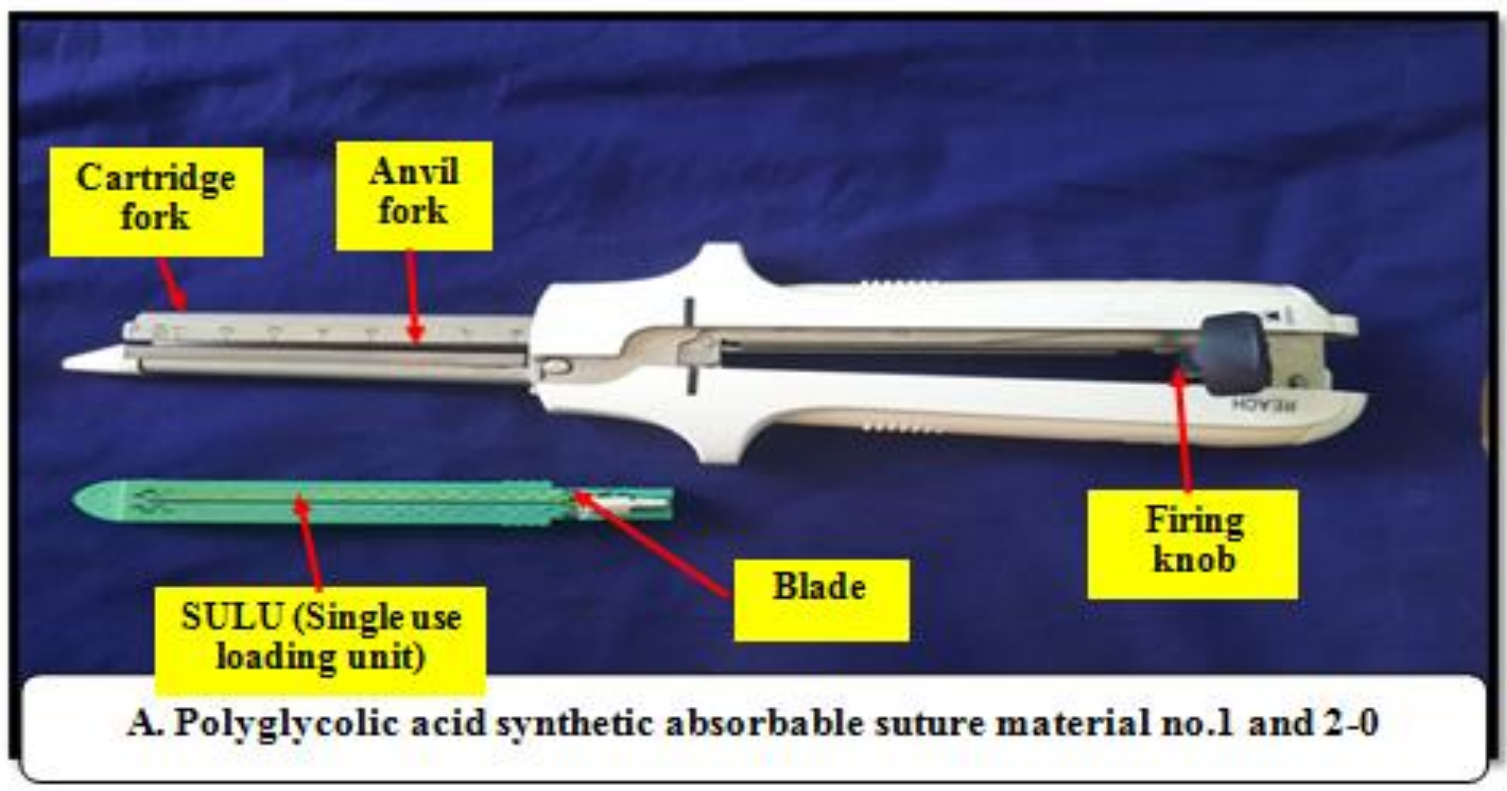

Fig.3 Ultrasonographic image of distended intestinal loops

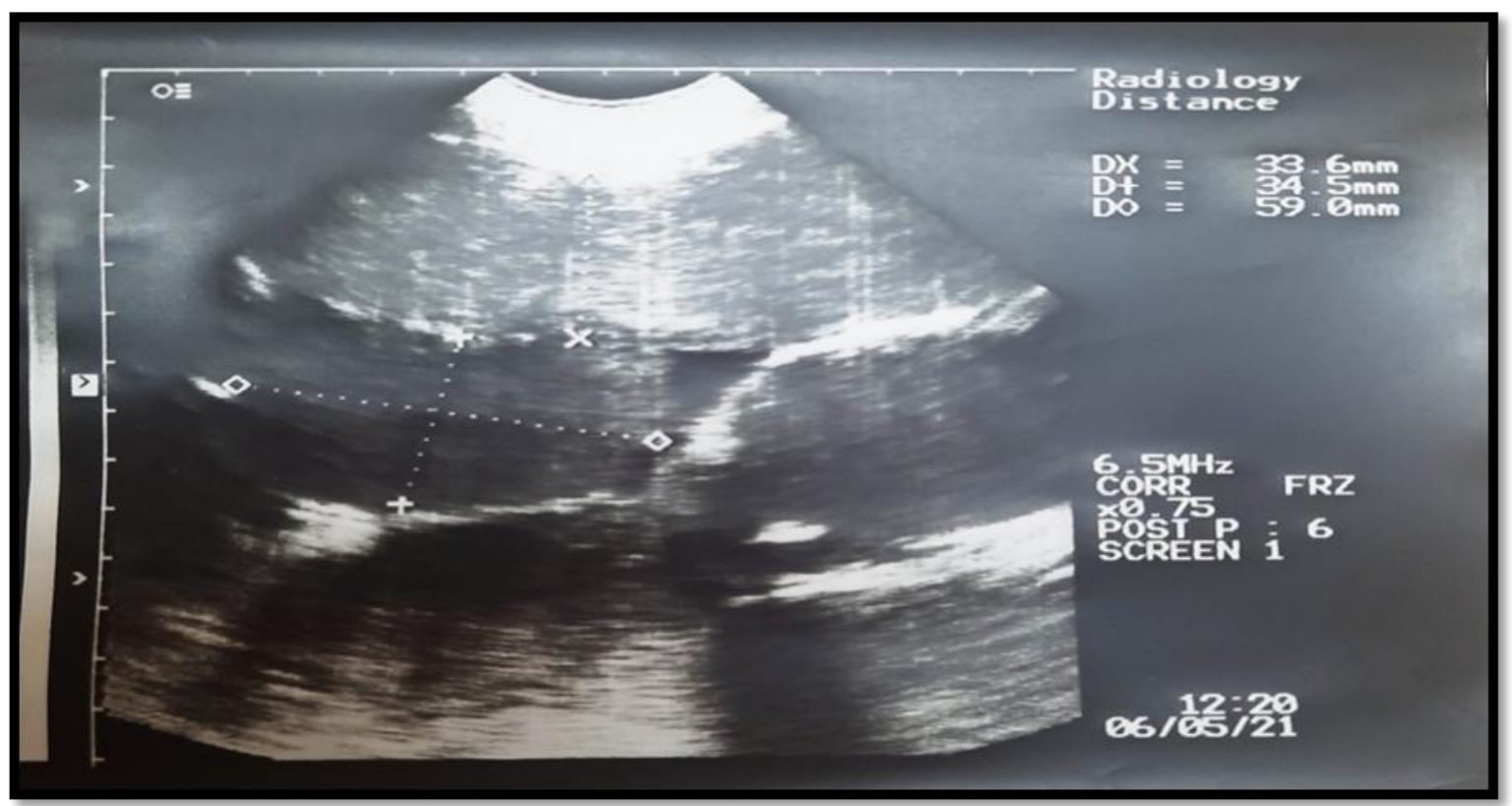

Presence of peritoneal fluid is attributable to transudation visible between the loops of intestines. This fluid appeared as hypo echoic. Intestinal contents appear echogenic as compared to peritoneal fluid outside the intestinal wall. There was passive movement of ingesta found in the longitudinal section of the intestine. This might have happened due to excessive entrapment of fluid and gases as well as ingesta in the lumen of the intestinal segments proximal to the site of the obstruction. However, such findings could not 
be confirmatory to intestinal intussusception as these may be observed in any case of intestinal ileus (Imran et al., 2011; Tharwat, 2012; Mestry et al., 2012; Khalphallah et al., 2016; Mir, 2018 and Mann et al., 2019).

Total duration of surgery (min) was $(31.80 \pm$ $0.97)$ and anastomotic time $(\mathrm{min})$ was $(5.60 \pm$ 0.22 ). This might be due to fully mechanized working of GIA stapling device. The use of stapling devices reduces the surgical time. Tissue damage is reduced by using stapling devices because tissue manipulation is less (Ravitch and Stechen, 1972) and less time is spent in physically handling the tissue/bowel. Similar findings were reported by previous authors (White, 2008; Tobias, 2008; Changal, 2010; Jardel, 2011; Lipscomb, 2012; Bhandary et al., 2016 and Banurekha et al., 2017).

Intestinal intussusception in dairy heifers could be diagnosed on the basis of history, clinical signs, per-rectal palpation, transabdominal ultrasonography which could be further confirmed by full abdominal right flank exploratory laparotomy. The GIA staples applied for side-to-side entero-anastomosis by open lumina technique took less total surgical, anastomotic time and stapling time as well as there was reduction in tissue trauma/manipulation and contamination by intestinal contents. The closure of the bowel was easy and secured. GIA staples can be used effectively for entero-anastomosis in cattle affected with intestinal intussusception.

\section{References}

Agne, G. F., Stockler, R. M., Passler, T., Maxwell, H. and Cole, R. 2018. Successful surgical resolution of a ceco-cecal intussusception in a 15month-old Angus heifer. Canadian Veterinary Journal, 59:1071-1074.

Banurekha, R., Sadasivam, S. and
Sathyamoorthy, K. 2017. Hand sewn versus stapler anastomosis in elective gastro intestinal surgeries. International Surgery Journal, 4(7):2316-2320.

Bhandary, S., Babu, N. M., Gojanur, G. and Reddy, C. K. 2016. Comparative study of bowel anastomosis - hand sewn versus stapler. IOSR Journal of Dental and Medical Sciences, 15(12):37-42.

Changal, N. A. 2010.Comparison of surgical stapling with routine sutures for enteroanastomosis in cattle. M.V.Sc thesis, Sher-e- Kashmir University of Agricultural Sciences and Technology, Jammu, India.

Chassin, J. L., Rifkind, K. M. and Turner, J. W. 1984. Errors and pitfalls in stapling gastrointestinal tract anastomoses. Surgical Clinics of North America, 64: 441-459

Constable, P. D., St. Jean G.; Hull, B. L., Rings, D. M., Morin, D. E. and Nelson, D. R. 1997. Intussuception in cattle: 336 cases (1964-1993). Journal of American Veterinary Medical Association, 210:531-536.

Dabak, M., Unsaldi, E. and Gul, Y. 2001. Diagnosis and treatment of intussusception in a cow. Turkish Journal of Veterinary and Animal Science, 25:387-389.

Dharmaceelan, S., Rajendran, N., Nanjappan, K., Subramanian, M. and Balasubramaniam, G. A. 2012. Incidence of bovine gastrointestinlal obstruction in a teaching veterinary hospital of Tamil Nadu, India. International Journal of Veterinary Science, 1(3): 112-114.

Fontaine, G. and Rodgerson, D. H. 2001. Diagnosis of small intestine intussusception by transabdominal ultrasonography in two adult horses. Canadian Veterinary Journal. 42:378380. 
Horne, M. M. 1991. Colonic intussusception in a Holstein calf. Canadian. Veterinary Journal, 32: 493-495.

Hussain, S. A., Uppal, S. K., Randhawa, C. S. and Sood, N. K. 2015. Bovine intestinal obstruction: blood gas analysis, serum C-reactive protein and clinical, haematological and biochemical alterations. Journal of Applied Animal Research, 43(2): 224230.

Imran, S., Tyagi, S. P., Kumar, A., Kumar, A., Sharma, A. and Sharma, S. 2011. Usefulness and limitation of ultrasonography in the diagnosis of intestinal intussusception in cows. Veterinary Medicine International, 2011:1-6.

Jardel, N., Hidalgo, A., Leperlier, D., Manassero, M., Gomes, A., Bedu, A.S., Moissonier, P., Fayolle, P., Begon, D., Riquois, E. and Viteau, V. 2011. One stage functional end-to-end stapled intestinal anastomosis and resection performed by non-expert surgeons for the treatment of small intestinal obstruction in 30 dogs. Veterinary Surgery, 40:216-222.

Khalphallah, A., Aref, N. M., Elmeligy, E. and EL-Hawari, S. F. 2016. Clinical and ultrasonographic observations of functional and mechanical intestinal obstruction in buffaloes (Bubalus bubalis). Veterinary World, 9(5):475480.

Kushwaha, R. B., Gupta, A. K., Bhadwal, M. S., Bhardwaj, H. R., Tripathi, A. K. and Sharad, K. 2012. Intestinal obstruction due to intussusception in cattle: a clinical study on 20 cases. Indian Journal of Veterinary Science, 33(1):63-65.

Lipscomb, V. 2012. Surgical staplers: toy or tool?. Companion Animal Practice, 34: 472-479.

Mcginty, C. P., Kasten, M. C., Kinder, J. L. and Hunt, R. S. 1979. Update on stapled bowel anastomosis. Modern Medicine, 76:145-150.

Mann, J. S., Kumar, A., Bharadwaj, H. R. and Nashiruddullah, N. 2019. Study on biophysical dynamics of rumen in cattle suffering from small bowel intussusception. International Journal of Current Microbiology and Applied Sciences, 8(8): 647-665.

Mestry, G. R., Patel P. B., Patel, J. B., Mistry, J. N. and Suthar, D. N. 2012. Intestinal obstruction in bovines and its surgical management - A Clinical report of 12 cases, Intas Polivet, 12(2):308-312.

Milnes, E. L. and McLachlan, A. 2015. Surgical management of small intestinal intussusception associated with jejuna adenocarcinoma in a dairy cow. New Zealand Veterinary Journal, 63(5):288-290.

Mir, L. A. 2018. Pain assessment and its management in cattle undergoing right flank laparo-enterectomy. M.V.Sc Thesis, Sher-e-Kashmir University of Agricultural Sciences and Technology, Jammu, India.

Nance, F. C. 1979. New techniques of gastrointestinal anastomoses with the EEA stapler. Annals of Surgery, 189:587-600.

Nichols, S. and Fecteau, G. 2017. Surgical management of abomasal and small intestinal disease. Veterinary Clinics of Food Animals, 34(1):55-81.

Papadopolous, P., Raptopouloas, D., Dessiris, A. and Tsimopoulos, G. 1985. Experimental intestinal obstruction in cattle part: Changes in the clinical picture. Journal of Veterinary Medicine, 32:264-275.

Patel, J. B., Abhishek, M. P., Sutaria, P. T., Patel, P. B. and Patel, A. M. 2019. A new technique for correction of intussusception in kankrej bullock. International Journal of Current 
Microbiology and Applied Science, 8(3): 2108-2110.

Pearson, H. 1971. Intussusception in cattle. Veterinary Record, 89:426-437.

Ralphs, S. C., Jessen, C. R. and Lipowitz, A. J. 2003. Risk factors for leakage following intestinal small animal's anastomosis in dogs and cats: 115 cases (1991-2000), Journal of the American Veterinary Medical Association, 223(1):73-77.

Ravitch, M. M. and Stechen, F. M. 1972 Techniques of staple suturing in the gastrointestinal tract. Annals of Surgery, 175: 815-837.

Ravitch, M. M., Ong, T. H. and Gazzola, L. 1974. A new precise and rapid technique of intestinal resection and anastomosis with staples. Surgical Gynecology and Obstetrics, 139: 6-10.

Santo, M. A., Takeda, F. R. and Sallum, R. A. A. 2011. Staplers in digestive surgery. Technological advancement in surgeon's own hands. Arquivos de Gastroenterologia, 48(1):1-2.

Smart, M. E., Fretz, P. B., Gudmundson, J. and Cymbaluk, N. 1977. Intussuception in a charolais bull. Canadian Veterinary Journal, 18:244246.

Smeak, D. D. and Crocker, C.1997. Fixedhead staplers: features and performance. Compendium on Continuous Education for the Small
Animal Practice, 19:1358-1369.

Smith, B. P. 2014. Large Animal Internal Medicine. 5th ed. pp-820 Mosby, St. Louis.

Smith, D. F. 1980. Intussusception in adult cattle. Compendium on Continuing Education for the Practicing Veterinarian, 2: 549-553.

Steichen, F. M. and Ravitch, M. M. 1984. Operations on the small and large bowel. In: Stapling in Surgery. Chicago, IL, USA, Year Book Medical Publishers. Pp: 270-310.

Ullman, S. L. 1994. Surgical stapling of the small intestine. Veterinary Clinics of North America: Small Animal Practice, 24:305-322.

Tharwat, M. 2011. Diagnostic ultrasonography in cattle and buffaloes with intestinal obstruction. Journal of Agriculture and Veterinary Science, 4 67-80.

Tobias, K. M. 2007. Surgical stapling devices in veterinary medicine: A review. Veterinary Surgery. 36: 341-349.

White, R. N. 2008. Modified functional endto-end stapled intestinal anastomosis: technique and clinical results in 15 dogs. Journal of Small Animal Practice, 49: 274-281.

Yamamoto, T. and Keighley, M. R. 1999. Stapled functional end-to-end anastomosis in Crohn's disease. Surgery Today, 29: 679-681.

\section{How to cite this article:}

Sukhnandan Singh, H. R. Bhardwaj, M. M. S. Zama, Ankur Sharma, Pankaj Gupta, Ashok Kumar and Kamal Sarma. 2021. Diagnosis and Surgical Management of Intestinal Intussusception by Open Lumina Technique in Dairy Heifers (Bos taurus). Int.J.Curr.Microbiol.App.Sci. 10(11): 250-258. doi: https://doi.org/10.20546/ijcmas.2021.1011.029 